\title{
A Preliminary Evaluation of Elementary School Teachers Willingness to Gain Certification in Science or Mathematics in an Effort Towards Achieving School- wide STEM Certification (RTP, Strand 3)
}

Dr. Stephanie C. Vereen, University of Alabama

Dr. Vereen is an Assistant Professor in the Department of Civil, Construction, and Environmental Engineering at the University of Alabama. Her research focus is on ensuring a sustainable and resilient workforce for engineering and skilled labor occupations.

Ms. Allison D. Vereen, North Douglas Elementary, Douglas County School System

Ms. Vereen is an Instructional Lead Teacher at North Douglas Elementary located in Douglasville, Georgia. She is currently a doctoral candidate at Georgia Southern University pursuing an Ed.D. in Curriculum Studies. 


\section{A Preliminary Evaluation of Elementary School Teachers Willingness to Gain Certification in Science or Mathematics in an Effort Towards Achieving School- wide STEM Certification (RTP, Strand 3)}

Teacher buy-in is critical to the success of achieving elementary school STEM certification in the state of Georgia. The goal of the certification program is to provide educational opportunities in which students are prepared as $21^{\text {st }}$ century learners. More than 75 percent of a school's staff must have a science or math endorsement or middle school science or math certification (by passing the middle school GACE, Georgia Assessments for the Certification of Educators) or are working on that endorsement/certification for a school to attain this status. The State of Georgia has an initiative to increase the number of students prepared for and enrolled in STEM degree programs. This initiative was developed in response to the critical need for science, technology, engineering, and mathematics (STEM) graduates to ensure the future success of the state's workforce. In addition, there is a necessity to develop the quantity and quality of Georgia's P-12 science and mathematics teachers. This study focuses on evaluating early education teachers' willingness to receive STEM education training, receive assistance with introducing and implementing STEM concepts to their students on a daily basis in their classrooms, and also to identify challenges to their willingness to embrace new curriculum concepts. A survey was developed to assess teachers' comfort levels with science, technology, math, and science education, and their willingness to receive additional training, if necessary, in one Title I Georgia elementary school. Preliminary survey results indicate that the majority of teachers had a mediocre level of interest and willingness to receive additional training. This study will present the final results of a school-wide survey as well as identify challenges, and benefits for further teacher engagement and buy-in towards the achievement of STEM certification for this school which will be applicable and beneficial to other elementary schools with similar demographics.

RTP Strand 3 - Principles of K-12 Engineering Education and Practice

- Papers in this strand contain research focusing on developing engineering habits of mind in teachers and students. These engineering habits of mind include learning from failure, teamwork and collaboration, and engaging in physical testing.

KEY WORDS: STEM initiative, P-12 education, Teacher willingness 


\section{Background and Introduction}

The state of Georgia has an initiative to increase the number of students who are adequately prepared for and will eventually enroll in college degree programs focusing on Science, Technology, Engineering, and Mathematics (STEM). The rapid evolution of technology and need for continuing innovations "suggests that students entering higher education must be prepared differently at pre-kindergarten through 12 th grade $(\mathrm{P}-12)$ levels if they are to be ready for the transition into undergraduate institutions working to provide a diverse STEM talent pool"2. The motivation for developing the initiative was to respond to the critical need for STEM graduates who will eventually enter and sustain a skilled workforce in the state. In order to achieve results in the long term, the state is focusing on the present development of both the quantity and quality of Georgia's science and mathematics teachers at the preschool through $12^{\text {th }}$ grade levels. The rationale is that increasing the quality of STEM education increases the quality and adequacy of student preparedness in STEM fields. As a result, enrollment in higher education increases thereby affecting the quality and quantity of STEM entrants into the workforce.

This initiative, referred to as STEM Georgia, has several goals including empowering students to become innovators and problem solvers, increasing student's 21 st century skills, and increasing Georgia's capacity to provide high quality K-12 STEM professional learning opportunities ${ }^{1}$. One component of STEM Georgia, implemented as a result of the intended long term objective of developing and ensuring a skilled STEM workforce, is STEM certification for elementary, middle, and high schools throughout the state of Georgia. One of the primary goals of STEM certification is to increase the number of students pursuing careers in STEM-related fields and/or post-secondary STEM related education/training ${ }^{1}$.

"Well educated, specialist teachers of [STEM] disciplines are the critical link for the next STEM generation", To obtain Georgia STEM certification at the elementary level, a critical component is that more than 75 percent of a school's staff must have or be working towards achievement of either a science or math endorsement, or middle school science or math certification. The endorsement is achieved by completing more than 160 hours of coursework in a certified endorsement program, while the certification is achieved by passing the middle school Georgia Assessments for the Certification of Educators (GACE). Teachers in the state of Georgia are only required to maintain teacher certification as determined by the Georgia Professional Standards Commission. The specific science or math endorsement or certification is not a requirement of sustaining teacher certification. However, after both the teachers and the school achieve certification, teachers must be willing to receive additional training and feedback on implementing classroom tools and techniques to achieve the goals of the STEM certification program.

"To engage children and adolescents in STEM requires teachers with pedagogical as well as content expertise" STEM curriculums into P-12 education, however, there has been little to no discussion on the role of the teacher or a teachers' willingness to get additional training in order to implement new curriculum, techniques, and extracurricular programs to actively work towards increased STEM in current curricula. Teacher buy-in is critical to the success of schools achieving the STEM 
certification. Teachers must be motivated and willing to obtain the necessary endorsement or certification if they do not already have it. "Education research shows that instructional practice and teacher decision making are influenced by teachers' beliefs about learning and instruction". The purpose of this study is to demonstrate teachers' willingness to work towards the goals of a Title I elementary school's attempt at STEM certification with widespread implementation into existing daily curriculum and expansion of extracurricular activities.

\section{Results and Analysis}

The study presented herein is based on teacher evaluations of a Title I elementary school in Georgia that is interested in working towards STEM certification. The certification is a lengthy and arduous process and requires the dedication and leadership of a concerted group of champions. Thus, a committee was developed at the school with the specific aim of working towards goals and initiatives to obtain the certification. The committee consists of the principal, assistant principal, media specialist, gifted teacher, and the instructional lead teacher. The committee began by working towards implementing multiple science initiatives at the school such as K-5 Science Lab, a Lego robotics team, and Science Olympiad team.

To assess teachers' willingness to support the school's goal of attaining the state STEM certification, a survey was developed by the committee. In conjunction with the goals and initiatives of the committee, they developed a survey to achieve the following objectives:

1. to determine the feasibility of teachers transitioning their classes into science labs if provided adequate resources for hands on labs and activities

2. assess the willingness for teachers to volunteer additional time after school and weekends if additional activities, such as Science Olympiad and robotics team, were created

3. assess teachers being open to pursuing additional education by way of an endorsement class in either math or science or taking the content specific GACE in order to help the school achieve the STEM school certification

The objective of the survey was to evaluate early education teachers' willingness to, not only obtain the required endorsement or certification, but to receive training in STEM education. The teachers would further be required to introduce and implement STEM concepts to their students on a daily basis in the classroom. Additionally, the survey evaluates their willingness to implement new techniques and tools into their daily curriculum and also to participate in extracurricular activities outside of the classroom (such as Science Olympiad). It is not enough to simply state that a school will achieve certification without investigating the additional underlying efforts and commitments of teachers time and resources.

The committee distributed the survey to every certified teacher in the school (approximately 50 staff members including classroom teachers, specialists, special education teachers, guidance counselor, and speech teachers in kindergarten through $5^{\text {th }}$ grade). The survey was distributed via e-mail containing a web link to an online survey (Survey Monkey). Participation in the survey was optional and the response rate was approximately 50\%. Respondents could provide their name, but it was not required. No other demographic information was collected from respondents. 
Participants were asked to respond to one question in which they were asked to rank their interest in Science, Technology, Engineering, and Math from 1 to 4, where 1 indicated most interested and 4 indicated least interested. Figure 1 shows the results of that question.

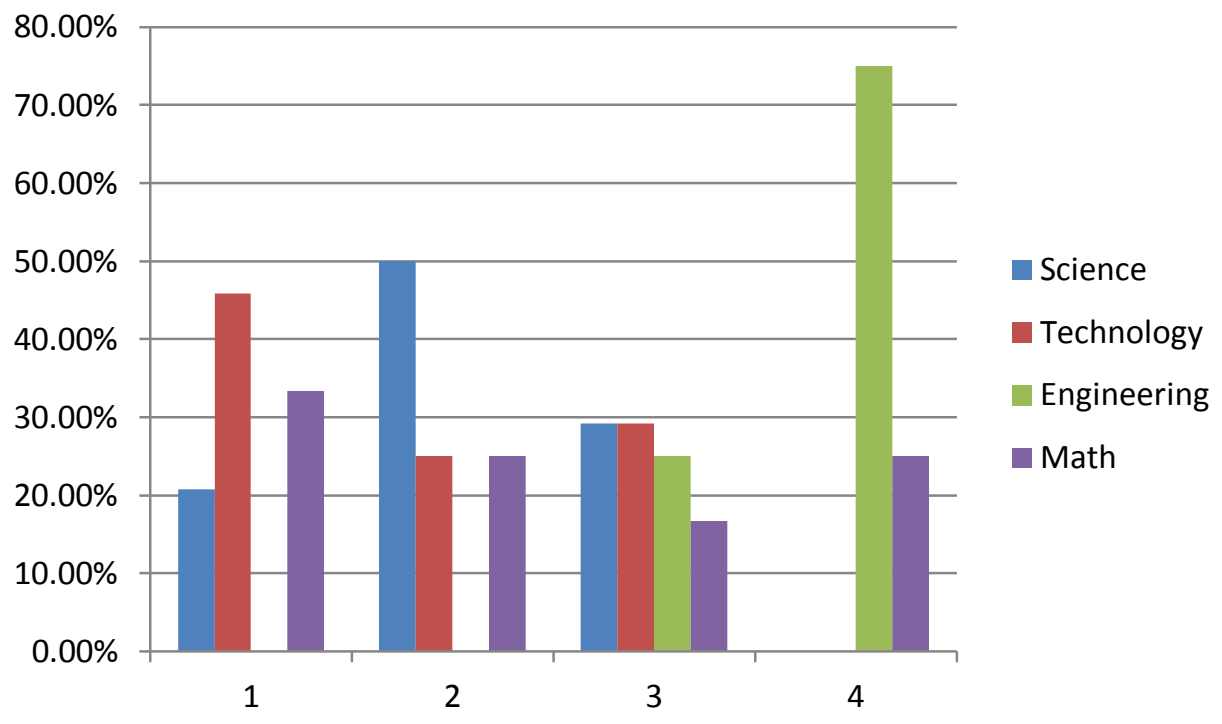

Figure 1. Question 1 Results

The majority of respondents indicated they were most interested in technology, followed by math, and then science. No respondents indicated the highest level of interest in engineering. Many school systems and states include "math" and "science". Most elementary school teachers do not have engineering training ${ }^{6}$ so often when teachers hear "engineering" they think the subject involves more than they are capable of teaching and is therefore out of their comfort zone and abilities. As noted in the conclusions, efforts will be made by the planning to committee to address this perception.

Approximately half of the teachers were interested in pursuing a Math or Science endorsement if there were local opportunities. The percentage of teachers willing to pursue professional opportunities increases to $58 \%$ when a stipend was specifically mentioned. It is important to note that current teacher participation in extracurricular activities is traditionally low if compensation is not provided (via Title I funding or other sources). Approximately $63 \%$ of teachers were willing to apply new knowledge to support students in STEM extra-curricular activities and $72 \%$ would be willing to use a STEM lab as part of their curriculum on a weekly basis.

Four additional questions were asked which required a yes or no response only. Table 1 shows a summary of the remaining questions and responses. 
Table 1. Additional Survey Questions

\begin{tabular}{|c|c|c|}
\hline QUESTION & YES (\%) & NO (\%) \\
\hline $\begin{array}{l}\text { Would you be interested in obtaining an } \\
\text { endorsement in either Math or Science if } \\
\text { the classes were offered locally? }\end{array}$ & 47.83 & 52.17 \\
\hline $\begin{array}{l}\text { There are many professional opportunities } \\
\text { about STEM available through Georgia } \\
\text { Tech, University of West Georgia, etc. } \\
\text { Would you be interested in attending } \\
\text { events on a Saturday or during the } \\
\text { summer if a stipend was available? }\end{array}$ & 58.33 & 41.67 \\
\hline $\begin{array}{l}\text { Would you be willing to use the } \\
\text { knowledge you will obtain through the } \\
\text { professional learning to support students } \\
\text { in extra-curricular activities pertaining to } \\
\text { STEM? }\end{array}$ & 62.50 & 37.50 \\
\hline $\begin{array}{l}\text { Would you be willing to use a STEM lab } \\
\text { as part of your curriculum on a weekly } \\
\text { basis? }\end{array}$ & 72.73 & 27.27 \\
\hline
\end{tabular}

One of the issues with teacher apathy as evidenced by moderate survey results is the plethora of initiatives, other than STEM, in which they are required to implement. For example, common core standards were introduced 2 years prior and teachers are still trying to familiarize themselves with these new standards. Thus introducing new concepts and training requirements for the purposes of STEM certification may seem burdensome.

\section{Conclusions \& Recommendations}

The key findings of the study presented herein are that teachers have a moderate willingness to work towards the achievement of STEM certification. Barriers to increased willingness and participation include committing to uncompensated training and overburdening teachers with a new way of teaching curriculum. Long term efforts will be recognized in the goals of the state of Georgia STEM initiatives. However, short term, administrators, teachers and instructional specialists need to be cognizant of unanticipated obstacles such as teacher's hesitation to work towards the goals.

The efforts presented in this paper highlight the goals and challenges of achieving STEM certification at a Title I elementary school in Georgia. Based on the results of the researcher's survey, it is our belief that teachers would be more receptive to the implementation of STEM 
initiatives if they were more knowledgeable regarding the alignment of STEM and the common core standards that they are required to teach.

As previously stated, a critical component is that more than $75 \%$ of a school's certified staff must have a science or math certification or endorsement or be working towards one or the other. Based on the survey, the $75 \%$ would not be achieved. Despite survey results, the committee and school leadership team are still moving ahead with the initiatives because they are desperately needed. The next steps for the school are going to be to move forward with attempting to achieve the certification and also implementing other STEM activities. It is noted that the response rate to the initial survey was low so it may be redistributed in the future to see if the participation rate increases.

Because of the indication of low motivation and willingness of teacher participation in the planned efforts, the leadership team is implementing steps to increase teacher motivation to support the initiative, both morally and financially. Informal discussion and follow up among the committee, school leadership, and teaching and support staff indicated an attitude that the initiative will simply be more work with no (financial) incentive. The reality is, if the majority of teachers already feel that they giving maximum effort for minimal pay, this does not create an environment where teachers are willing to attend extra trainings as what is perceived to be "for free" by way of time commitments after school or on weekends with no compensation. As noted below, part of the planning effort includes application for external funding to supplement teacher income, which although not captured in the formal questionnaire, is a motivator for some based on informal conversation amongst staff.

Another important lesson learned is the proposed initiative, and similar initiatives in other school districts and states, require additional teacher training (in the proposed fields and also in the creation and implementation of applicable lesson plans) and buy-in (positive attitude) to be successful. The message must be communicated to teachers that such initiatives are designed to enhance their classroom experience by modifying existing lessons, not adding additional lessons. A shift in the perceptions and perceived benefits is essential to the success of such initiatives in this, and in any school environment. The committee is planning a series of brief, informal small group meetings with teachers to present the benefits and positive outcomes of moving forward with the initiative, answer any outstanding questions, and address any concerns related to the proposed program. These sessions will also be used to define the "engineering" component of STEM. This is aimed at increasing confidence in teachers who may not feel comfortable with teaching "engineering". Based on other studies ${ }^{6}$, the committee has informally discussed soliciting support from community volunteers and local college students to assist teachers in the classroom. Also, the instructional lead teacher will conduct model lessons in classes throughout the school to provide examples of lessons and activities that can be facilitated in existing curriculum. It is anticipated that student enthusiasm and engagement in these lessons will, in turn, increase teacher motivation to engage with the program.

The results of the survey, as noted, are also being used to pursue additional funding opportunities to support the goals and objectives of the committee. Grants have been submitted through Google Community Grants and Project Lead the Way (PLTW), national initiatives that have the potential to provide over $\$ 25,000$ of funding if received. The primary goal of funding will be to 
create a K-5 STEM lab, which would be equipped for teachers to bring their classes and conduct activities. The secondary goal of funding will be extracurricular activities and additional pay for teacher training. Rogers and Portsmore ${ }^{4}$ note that "making a systemic change in curriculum requires a large effort on the part of the teachers, administrators, parents, and the kids and takes a long time to happen. It requires continual financial support and, when it is something completely new, it requires intellectual support". It is anticipated that receiving additional funds from nonprofit sources, such as community grants, will increase teacher's willingness to participate in obtaining additional training for implementation of STEM activities in the classroom because course fees are covered and resources are provided.

As other elementary schools work towards similar initiatives, it is the researcher's recommendation that they should focus on teacher's understanding of:

- the individual components of science, technology, engineering, and math (STEM) and how each area is defined

- the ease of which STEM can be integrated into the common core standards which they are required to teach.

- the long term benefits of preparing students for their futures as 21 st century learners.

Additional lessons learned will be documented and assessed throughout the course of program implementation, such that they can be catalogued for the benefit and application by the larger K12 Education community.

\section{References}

[1] GA STEM. "Georgia STEM Goals, Institute, Festivals, Certifications, \& Webinars", http://stemgeorgia.org/georgia-stem-initiatives/ Accessed January 29, 2015.

[2] Brophy, S., Klein, S., Portsmore, M, and Rogers, C. (2008), "Advancing Engineering Education in P- 12 classrooms."Journal of Engineering Education, Volume 97. Issue 3, Pages 369-387.

[3] Nathan, M.J., Tran, N.A., Atwood, A.K., Prevost, A., Phelps, L.A. (2013) "Beliefs and Expectations About Engineering Preparation Exhibited by High School STEM Teachers" Journal of Engineering Education, Volume 99, Issue 4, Pages 409 - 426.

[4] Rogers, C. and Portsmore, M. (2004) "Bringing Engineering to Elementary School" Journal of STEM Education. Volume 5.

[5] Watt, H.M.G., Richardson, P.W., and Pietsch, J. (2007), "Choosing to Teach in the "STEM" Disciplines: Characteristics and Motivations of Science, ICT, and Mathematics Teachers." Mathematica: Essential Research, Essential practice 2, Pages 795-804.

[6] Portsmore, M. D., and C. Rogers.(2004) "Bringing engineering to elementary school."Journal of STEM education, 5. 